mina a inevitabilidade de sua decadência, que constitui apenas tendência para certos casos.

Procuramos destacar aspectos que mais nos chamaram a atenção na obra, o que de modo algum esgota as várias contribuições que traz.

A comparação das concepções de vários autores sobre bairros rurais, o questionamento de certo tipo de divisão econômico-social do Estado de São Paulo, a exposição dos métodos utilizados nas pesquisas, a caracterização dos municípios em que se localizam os bairros estudados, bem como a descrição detalhada destes últimos, do seu funcionamento, das relações com os núcleos urbanos e regiões, são outras tantas contribuições a assinalar.

No entanto a obra parece-nos ser um tanto repetitiva nas análises e conclusões. No estudo de cada unidade pesquisada, repisam-se, de modo desnecessário, os pressupostos utilizados e as hipóteses que se vão formulando. As teses da autora, entretanto, contribuem para novas discussões sobre o bairro rural. Desta forma, a obra constitui mais uma contribuição à literatura existente e sua leitura é necessária para o estudo do problema do bairro rural.

Marisa Saenz Leme

\section{Brancos e Pretos na Bahia}

Por Donald Pierson. 2 ed. São Paulo, Companhia Editora $\mathrm{Na}$ cional, 1971. 430 p. (Coleção Brasiliana, v. 241).
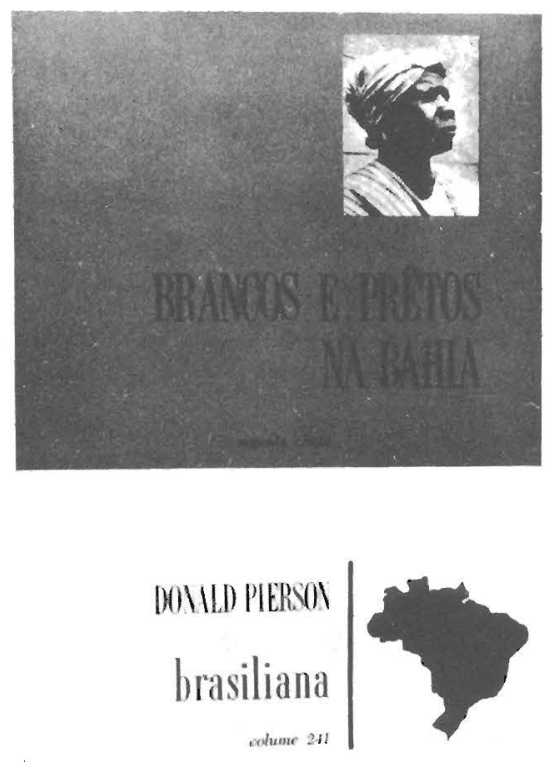

Enquanto na década de 30 proliferavam no Brasil estudos culturalistas sobre os negros, enfatizando aspectos religiosos, folclóricos, lingüísticos, etc., o tema "negro" mantinha-se excluído das preocupações sociológicas da época, então essencialmente ensaísticas.

Esta obra de Donald Pierson, baseada em pesquisas realizadas entre 1935 e 1937 na Bahia, surgiu como trabalho isolado, posto que orientada de modo totalmente original. $O$ autor vinha ao Brasil fundamentado na sociologia americana incrementada por Robert Park, Robert Redfield, Louis Wirth, Herbert Blumer e outros. Desenvolveu observação cuidadosa, procurou conseguir intimidade com o objeto de análise residindo em diferentes pontos da cidade de Salvador, participando tanto quanto possível das atividades culturais da população de cor; estudou documentos e levantou dados sobre a distribuição da pupulação na cidade, as atividades econômicas mais características, etc.; valeu-se de questionários aplicados a estu- dantes e de entrevistas diversas, depoimentos escritos, enfim, conseguiu reunir uma massa de dados empíricos totalmente inédita, a que conferiu tratamento estatístico. Talvez este seja seu maior mérito. Além disso, considerou em larga escala os estudos feitos anteriormente sobre o assunto, quer por brasileiros, quer por estrangeiros, comparando os resultados que ia obtendo com os deles. Assumiu atitude durkheimiana diante do objeto de estudo, ao pretender isentar-se de envolvimentos emocionais ou valorativos, dispondo-se a descrever e analisar, tão-somente.

Pierson veio ao Brasil com o intuito de proceder a um estudo sistematizado e objetivo das relações de raça, pois aqui se apresentava um dos mais importantes melting-pots de raças e culturas, numa época em que, tanto a Europa quanto os Estado Unidos e outros, se viam às voltas com questões raciais. Foi justamente a ausência de "problema racial" no Brasil que chamou sua atenção. Percebe-se, por isso, que desde o início do trabalho houve um quadro de referências implícito, qual seja, o das relações raciais na sociedade com a qual o autor estava familiarizado: a norte-americana.

No decorrer de toda a obra há referências comparativas, que enfatizam ou reafirmam o caráter típico das relações raciais nas duas sociedades: a inexistência de uma "linha de cor" rígida, a organização social baseada em classes abertas, a política assimilacionista por parte dos "brancos" e a ideologia (não formal) da democracia racial, na sociedade brasileira; a demarcação rígida entre negros e brancos, a existência de verdadeiras castas separando esses grupos e a consciência dos negros como "minoria", nos Estados Unidos.

Pierson aponta as dificuldades que encontrou diante da necessidade de conceituar "cor" e "raça" na Bahia, pois não encontrou "grupos" característicos, de acordo com o sentido científico do termo e sim agregados estatísticos somente, visíveis apenas para o observador. Considerando 
inadequado o termo "raça", dado o grau de diluição provocado pela miscigenação, optou pela substituição por "cor"; mas ainda assim teve problemas, porque aqui ela não se refere apenas à aparência física, pois tem também significado social.

A discriminação com base na raça não faz parte dos mores brasileiros; é individual. É inegável que ela existe, de certa forma, na Bahia, quanto às pessoas de cor, mas isto não significa que haja preconceito - se este for tomado como um sentimento partiIhado por um grupo racial dominante, que se presume ameaçado, na sua posição privilegiada, por uma raça subordinada, sendo, portando, um mecanismo de defesa.

O caráter miscigenacionista da colonização portuguesa, fixado firmemente nos mores coloniais (os brancos assimilando os mulatos e estes, os negros), o freqüente estabelecimento de relações primárias e de afetividade entre senhores e escravos (domésticos, especialmente) e a própria passividade do negro brasileiro, teriam evitado o surgimento de antagonismos raciais aqui. Os que existem enquadram-se melhor numa categoria cultural, minimizados à medida que avança o processo de assimilação gradual e de ascensão social dos elementos de cor. Pierson compara, neste ponto, a formação de classes sociais no Brasil depois da Abolição (que foi processo gradual e generalizado ao País todo), com o período extremamente conturbado que sucedeu à Guerra de Secessão nos Estados Unidos, em que os antagonismos raciais puderam manifestar-se. No dizer do próprio autor, "não existem na Bahia 'castas' baseadas em raça; existem somente 'classes'. Isto não quer dizer que não exista discriminação em que estejam envolvidas pessoas de cor, mas sim que a discriminação existente é de 'classe' e não de 'casta'. E o tipo que existe entre os próprios homens de cor nos Estados Unidos, cuja intensidade é maior do que geralmente se pensa" (p. 353).

No Brasil, o passado "escuro" de uma pessoa é facilmente es- quecido, porque outros fatores como o nivel de instrução, o nivel econômico, o status ocupado, são mais importantes, conforme revelaram as pesquisas na Bahia. $\mathrm{Na}$ classe "inferior" inexiste o preconceito, acontecendo muitos casamentos mistos (o "branqueamento" da população é geralmente muito valorizado). Se eventualmente há oposição ao casamento com pretos, esta se baseia mais na situação de classe que em raça, propriamente. Assim também qualquer tratamento diferencial. A medida que a população de cor ascende na escala social, a tendência é então a maior diluição na cor. Portanto, a qualidade restritiva da cor, com seu sentido simbólico, pode ser vencida por qualidades outras, como a inteligência, fortuna, beleza, capacidade profissional, etc., como o autor pôde atestar na Bahia.

$A$ ascensão do negro se faz, no Brasil, com referência à comunidade total, e não como nos Estados Unidos, dentro dos limites do mundo de cor. Porque "... a organização social da Bahia tende a assumir a forma de uma ordem de livre competição, na qual os indivíduos encontram seu lugar pelos critérios da competência e realizações pessoais e circunstâncias fortuitas, mais que por sua origem racial" (p. 365).

Entretanto as pesquisas revelaram que ainda há uma coincidência extensa da cor com o status inferior, mas as exceções confirmam que existe a abertura (tratando-se, portando, de um sistema de classes e não de castas). A própria intelectualidade brasileira tem excluido de suas preocupações os problemas de conflitos raciais, apelando para questões etnológicas e históricas, que apontam as resistências culturais à assimilação (o interesse pelos aspectos sociológicos freqüentemente tem partido de elementos estranhos à cultura brasileira). Pierson indica que também não se ouve falar de descontentamentos e protestos por parte dos elementos de cor, principalmente daqueles que galgaram posições melhores, porque eles anseiam a assimilação. Se da parte de alguns emerge a consciência da seleção negativa, a identificação é de diferenças de classe e não de raça. Daí a não formação de uma "minoria racial" autoconsciente.

Baseado em amostragem da população em Salvador, o autor obtém a distribuição da população de cor por "classe social", concluindo que todas as cores estavam representadas em todas as "classes", ainda que os brancos ocupassem notadamente as camadas "superiores" e a gente de cor, as "inferiores" - isto se deve ao ponto de partida inferior e à existência de condições limitadas à melhoria ocupacional, escolarização, etc., na sociedade brasileira inclusiva.

Achamos oportuno indicar aqui alguns pontos que julgamos dúbios, equivocados ou esquecidos pelo autor, que, entretanto, relevamos ao considerar as qualidades inegáveis deste trabalho pioneiro, a que foi dada continuidade somente na segunda década seguinte, pelos sociológos de São Paulo. Pierson fala ao nível da consciência social dos "brancos" brasileiros dos círculos dirigentes, quando menciona o caráter relativamente "brando" da escravidão no Brasil, quando enfatiza a aceitação dos indivíduos pela sociedade em razão de qualidades psicológicas e sociais, as "vantagens" havidas para o negro pela manutenção dos laços paternalistas depois da Abolição, a existência somente do preconceito de classe, etc. Ora, de uma perspectiva mais atual e não influenciada pelo paradigma norteamericano de relações raciais, podemos contra-indicar: a) que por ocasião da Abolição manifestaram-se os interesses de setores econômicos fundamentais da nação, não importando o negro como homem; não houve crítica profunda da escravidão, nem se alteraram as posições ocupadas pelas antigas camadas sociais; a ordem senhorial e escravocrata foi em grande parte mantida; a alteração localizou-se apenas na esfera jurídica; b) faz parte da ideologia racial dos brancos a noção de que são os indivíduos os próprios responsáveis pelas posiçöes desvantajosas que ocupam na sociedade, pressupondo-se a 
livre concorrência entre todos, e não a predominância econômica e social do branco; essa posição isenta as elites brancas de res. ponsabilidade pela: situação dos negros; c) a luta pela ascensão social e econômica (o "branqueamento social") exige, para se alcançarem os traços qualitativos valorizados, o domínio de técnicas sociais a que os elementos de cor têm acesso muito mais dificilmente que os brancos (aquisição de instrução, formação de mentalidade de poupança, etc.), vindo isto a constituir um aspecto aberrante numa sociedade que se supõe competitiva; d) os indivíduos de cor que alcançavam meIhores posições identificavam-se totalmente com o mundo branco, dando lugar a uma acefalização da gente negra; geralmente esses elementos obtinham a solidariedade paternalista dos brancos (a propósito, vide, na obra em pauta, o apêndice A) e eram admitidos como exceção (a apatia e passividade dos outros negros era tacitamente preferida) - os brancos entre si é que competiam; e) se o preconceito é essencialmente de classe, deve cair quando é vencida a barreira da pobreza; mas quando negros e brancos se situam num mesmo nivel, os brancos são favorecidos - neste ponto, Pierson teria sido limitado pela escolha da Bahia, como área de estudo, ao invés do Rio de Janeiro ou São Paulo, onde os negros provavelmente ainda não tinham condições de participação plena.

162 Na introdução à presente edição o autor reconhece que muitos outros trabalhos mais completos foram realizados depois do seu, em vários centros nacionais e que no lapso entre a primeira e a segunda edição brasileira o processo de industrialização e urbanização deve ter afetado o contexto baiano, por isso retoma alguns aspectos. No todo, porém, não procedeu a alterações substanciais.

Marineide do Lago Salvador dos Santos

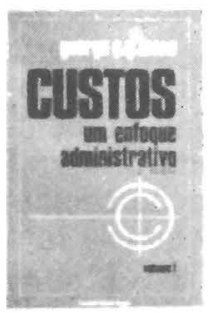

\section{CUSTOS - UM ENFOQUE}

Administrativo de George S.

Guerra Leone (2. edição, revista) - Um livro sobre contabilidade de custos destinado a professores e alunos das escolas de adininistração, a gerentes financeiros e tantos quantos lidem com custos e análise contábil e financeira.

\section{PESQUISA MERCADOLÓGICA}

de Boyd Westfall (2. ${ }^{\circ}$ ed.) Apresenta projetos de pesquisa e métodos para a coleta de dados junto ao mercado consumidor, aborda detalhadamente as fases de seu desenvolvimento, detendo-se nos métodos de amostragem aplicados à mercadização.

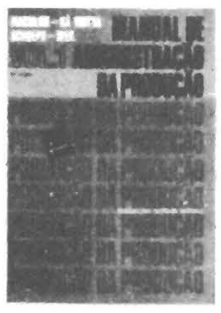

MANUAL DE ADMINISTRAÇĀO DA PRODução de Machline, Weil, Sá Motta e Schoeps ( 2 volumes) A orientação cienúfica, 0 tratamenco prospectivo dos temas, a preocupação com a atualização do quadro administrativo brasileiro e - sobretudo - a pertinente adequação dos temas à nossa realidade tornam esce manual imprescindivel a todo administrador industrial.

Procure essas obras nas boas livrarias.

Publicações da Fundação Getulio Vargas. 